\title{
Some psychological and physiological aspects of enteral nutrition
}

\author{
S P ALLISON \\ Queens Medical Centre, University Hospital, Nottingham
}

SUMmARY This review discusses three main topics: the first relates to the effects of underlying disease, malnutrition, and nutritional support on appetite; the second is concerned with the role of enteral feeding in short bowel syndrome; and the third deals with the clinical benefits of enteral nutrition.

\section{Psychological aspects: appetite}

It is common clinical experience to find that disease is associated with loss of appetite and weight. A typical patient is slow to recover from operation or acute illness and is depressed, apathetic, and anorectic. He has normal gastrointestinal and swallowing function but is unwilling to eat. Pressuring him causes distress and conflict with the nursing staff.

My first step is to discuss the situation with the patient to convince him that he is going to get better. Many patients seem to have been left in ignorance of the problem and have already decided that the end is near. It is important to exclude electrolyte disorders as sodium depletion, in particular, is a common cause of depressed mood and appetite. This patient would not have tolerated a wide bore nasogastric tube with bolus feeding. He would have found the tube uncomfortable and would have pulled it out "by accident." The bolus feeding would have given him diarrhoea, worsening rather than improving his clinical condition. He is, however, an ideal candidate for continuous infusion ${ }^{1}$ fine bore tube feeding, which he will probably tolerate well. $^{23}$

CASE 1

I first became aware of the relation between nutritional state and appetite when a young woman with Crohn's disease underwent panproctocolectomy and ileostomy in 1958. The disease recurred in 1972 with fistulae, pelvic abscesses, and electrolyte depletion, making her a chronic invalid for the next five years with a weight that rarely exceeded $48 \mathrm{~kg}$.

Correspondence to: Dr SP Allison, Queen's Medical Centre, University Hospital. Nottingham. NG7 2UH, England.
In 1978 she was given an intensive course of sip feeding ( $20 \mathrm{ml}$ every 15 minutes) over three weeks. As her weight passed the $52 \mathrm{~kg}$ mark it became unnecessary to push the feed as her voluntary oral intake rose steadily. Her weight has remained at 58 $\mathrm{kg}$ for the past seven years and she has led a normal life, feeling extremely well, with no hospital admissions and with normal biochemistry. This led me to the concept of primary and secondary anorexia (Fig. 1). Normal subjects maintain a steady relation between food intake and weight. Disease causes a primary loss of appetite with a consequent fall in food intake and weight. Beyond a certain point a secondary anorexia supervenes, similar in some patients to that seen in anorexia nervosa. Even when the acute disease episode has passed, a few patients are left with the appetite-weight relation

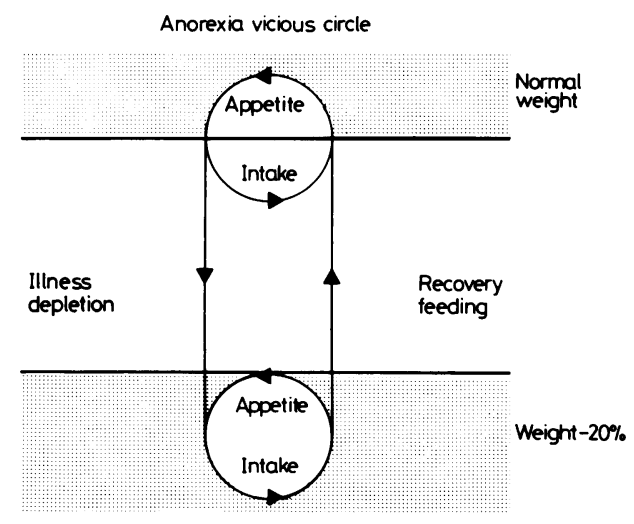

Fig. 1 Diagrammatic illustration of concept of primary and secondary anorexia. 
fixed at a lower level. This may be particularly striking in patients with inflammatory bowel disease.

We allowed patients free access to food during nasogastric feeding and observed that voluntary oral intake seemed to increase during the first two weeks of enteral feeding. This led us to adopt overnight tube feeding to release the patient for exercise and eating during the day. ${ }^{+}$Table 1 shows the ranges of voluntary oral intake before, and towards the end of, a period of nasogastric feeding in a group of patients with a recent history of anorexia and weight loss. In all cases there was an increase in voluntary oral intake, and in some cases this was doubled, at a time when nasogastric feeding was still being given. This contrasts with the common experience of parenteral feeding, which produces a weight gain but which may result in depression of appetite. In some cases we have even found it advantageous to bridge the gap between intestinal recovery and full oral feeding by changing from parenteral to overnight enteral nutrition and allowing free access to food by day. Voluntary oral intake is charted by the nurses and assessed by the dietitian each day. As soon as it reaches the patient's estimated metabolic requirements the tube feed is withdrawn. Enteral nutrition therefore seems to break the secondary anorexia in a way which suggests either an hormonally or neurally mediated mechanism, rather than a metabolic one, as it depends on the presence of food in the gastrointestinal tract.

\section{Overnight tube feeding}

Confining the tube feed to the night time and releasing the patient by day, not only gives more freedom for daytime eating, but is both psychologically and physically beneficial. Schonheyder et al ${ }^{5}$ showed large nitrogen losses in normal volunteers put to bed in plaster. Muscles, which are not exercised, waste, however good the nutritional treatment. For our patients on home tube feeding, the overnight feeding regimen is mandatory, not least because many of them work by day.

Our original policy of giving 2-3 litres of isomolar feed in 12 hours resulted in disturbed nights from the consequent diuresis and was superseded by a concentrated tube feed composed of oligosaccharide syrup and a high protein preparation to give $2000 \mathrm{kcal}(8.4 \mathrm{MJ})$ and $60 \mathrm{~g}$ of protein in a volume of $1000-1200 \mathrm{ml}$. The resulting mixture was hyperosmolar (454 mosmol $/ \mathrm{kg})$, but when delivered at a slow constant rate by pump over eight hours, it produced no diarrhoea, even in patients with short bowel syndrome. This emphasises the importance of osmoles administered per unit time rather than per unit volume. The normal gastrointestinal fluid turnover is so large that small volumes of concentrated feed are swiftly diluted to isosmolality (Fig. 2).

CASE 2 (Fig. 2)

This patient with Crohn's disease had lost his large

Table 1 Changes in voluntary oral intake in patients undergoing overnight nasogastric tube feeding

\begin{tabular}{|c|c|c|c|c|c|c|c|c|c|}
\hline \multirow[b]{2}{*}{ Patient } & \multirow[b]{2}{*}{ Diagnosis } & \multirow[b]{2}{*}{ Age } & \multirow[b]{2}{*}{$\operatorname{Sex}$} & \multirow{2}{*}{$\begin{array}{l}\text { Initial weight } \\
\text { ( } k g) \\
\text { (usual } \\
\text { weight) }\end{array}$} & \multirow{2}{*}{$\begin{array}{l}\text { Height } \\
(\mathrm{cm})\end{array}$} & \multirow{2}{*}{$\begin{array}{l}\text { Duration } \\
\text { of feeding } \\
\text { (days) }\end{array}$} & \multicolumn{2}{|c|}{$\begin{array}{l}\text { Voluntary food intake } \\
\text { (kcals) (range kj) }\end{array}$} & \multirow[b]{2}{*}{$\begin{array}{l}\text { Weight } \\
(\mathrm{kg})\end{array}$} \\
\hline & & & & & & & $\begin{array}{l}\text { Before tube } \\
\text { feeding }\end{array}$ & $\begin{array}{l}\text { End of tube } \\
\text { feeding }\end{array}$ & \\
\hline 1 & $\begin{array}{l}\text { Anorexia } \\
\text { nervosa }\end{array}$ & 15 & $\mathrm{~F}$ & $\begin{array}{l}36 \cdot 5 \\
(51)\end{array}$ & 167 & 43 & $\begin{array}{l}550-900) \\
(2100-3780)\end{array}$ & $\begin{array}{l}1500-2100 \\
(6300-8820)\end{array}$ & +11 \\
\hline 2 & $\begin{array}{r}\text { Anorexia } \\
\text { nervosa }\end{array}$ & 18 & $\mathrm{~F}$ & $\begin{array}{l}41 \\
(-)\end{array}$ & 157 & 21 & $\begin{array}{l}650-1200 \\
(273(1-5() 40)\end{array}$ & $\begin{array}{l}132(1-1950 \\
(5544-8190)\end{array}$ & $+8 \cdot 7$ \\
\hline 3 & $\begin{array}{l}\text { Anorexia } \\
\text { nervosa }\end{array}$ & 13 & $\mathrm{~F}$ & $\begin{array}{l}23 \cdot 7 \\
(-)\end{array}$ & 130 & 51 & $\begin{array}{l}475-1000 \\
(1995-4200)\end{array}$ & $\begin{array}{l}130(-1600 \\
5410-6720)\end{array}$ & $+7 \cdot 3$ \\
\hline 4 & $\begin{array}{c}\text { Anorexia and } \\
\text { depression }\end{array}$ & 53 & $\mathrm{~F}$ & $\begin{array}{l}41 \cdot 3 \\
(50)\end{array}$ & 160 & 21 & $\begin{array}{l}625-1400 \\
(2625-5880)\end{array}$ & $\begin{array}{l}14(0)-1900 \\
(580(0-7980)\end{array}$ & $+6 \cdot 3$ \\
\hline 5 & $\begin{array}{l}\text { Amyloid of } \\
\text { tongue }\end{array}$ & 63 & M & $\begin{array}{l}52 \cdot 3 \\
(60)\end{array}$ & 171 & 26 & $\begin{array}{l}125-850 \\
(525-3570)\end{array}$ & $\begin{array}{l}1300-1950 \\
(5460-8190)\end{array}$ & $+8 \cdot 7$ \\
\hline 6 & $\begin{array}{l}\text { Fractured } \\
\text { femur postoperative } \\
\text { anorexia }\end{array}$ & 79 & M & $\begin{array}{l}43 \\
(53)\end{array}$ & 165 & 10) & $\begin{array}{l}250-700) \\
(105(1-2940)\end{array}$ & $\begin{array}{l}120(0-2100 \\
(5040-8820)\end{array}$ & $+1 \cdot 0$ \\
\hline 7 & Crohn's disease & 49 & $\mathbf{M}$ & $\begin{array}{l}53 \\
(64)\end{array}$ & 170 & 24 & $\begin{array}{l}950-2750 \\
(399()-11550)\end{array}$ & $\begin{array}{l}27(0)-3800 \\
(11340-15960)\end{array}$ & +12 \\
\hline 8 & Carcinoma of vulva & 83 & $\mathrm{~F}$ & $\begin{array}{l}58 \cdot 5 \\
(66)\end{array}$ & 160 & 16 & $\begin{array}{l}60(1)-1300 \\
(252(1-5460)\end{array}$ & $\begin{array}{l}140()-1900 \\
(5880-7980)\end{array}$ & +3 \\
\hline 9 & Carcinoma of cervix & 78 & $\mathrm{~F}$ & $\begin{array}{l}37 \\
(-)\end{array}$ & 161 & 21 & $\begin{array}{l}580-1200 \\
(2436-5040)\end{array}$ & $\begin{array}{l}1200-1650 \\
(504()-6930)\end{array}$ & $+9 \cdot 2$ \\
\hline 10 & $\begin{array}{r}\text { Tuberculosis } \\
\text { peritonitis }\end{array}$ & 65 & M & $\begin{array}{l}53 \cdot 2 \\
(61)\end{array}$ & 178 & 17 & $\begin{array}{l}450-1100 \\
(1890-4620)\end{array}$ & $\begin{array}{l}140(0-2000 \\
(5880-8400)\end{array}$ & $+4 \cdot 3$ \\
\hline
\end{tabular}




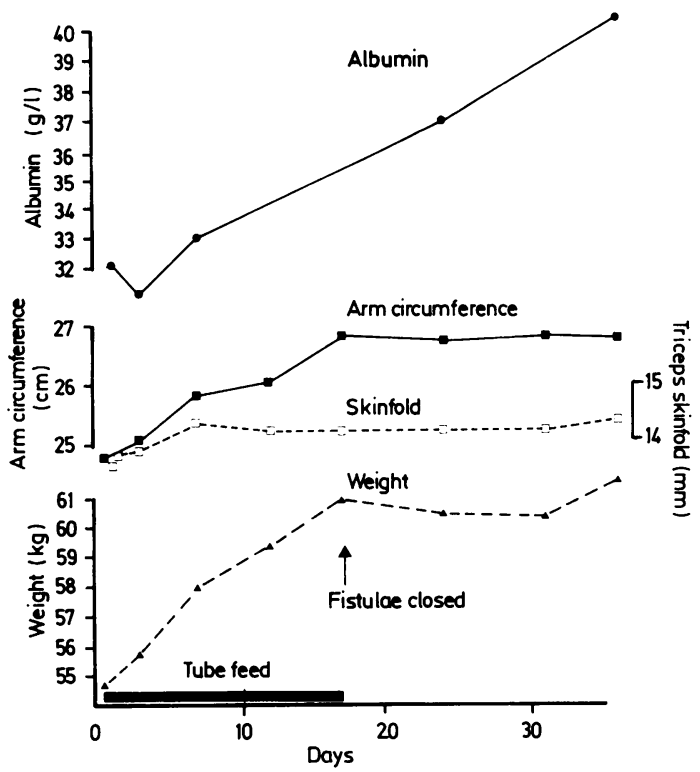

Fig. 2 Changes in nutritional variables with overnight nasogastric feeding $(2000 \mathrm{kcal})$ and daytime voluntary oral intake rising to $2500 \mathrm{kcal}$.

bowel and terminal ileum from surgery. A mid ileal ileostomy was surrounded by three separate fistulae. He had lost $10 \mathrm{~kg}$ in weight steadily over six months and was anorectic with a mean voluntary oral intake of $1300 \mathrm{kcal}(5.4 \mathrm{MJ}) /$ day. A $1200 \mathrm{ml}$ hyperosmolar overnight nasogastric feed provided $2000 \mathrm{kcal}$ $(8.4 \mathrm{MJ})$ and $60 \mathrm{~g}$ of protein without increasing his ileostomy output. He was ambulant and active by day. Within a week his voluntary oral intake had risen to $2500 \mathrm{kcal}(10 \cdot 6 \mathrm{MJ})$ giving a total energy intake of $4500 \mathrm{kcal}(18 \cdot 7 \mathrm{MJ})$. His fistulae closed, his weight and serum albumin concentration rose, and his arm muscle circumference rose by a proportionately greater amount than the triceps skin fold thickness, suggesting an important change in muscle mass.

\section{Short bowel syndrome}

Long term survival without parenteral nutrition is possible even with only two feet of small bowel. Although in the early stages after bowel resection parenteral nutrition may be necessary, adaptation and hypertrophy of the remaining bowel takes place over the ensuing weeks. ${ }^{6}$ This process is greatly enhanced by the presence of food in the gut so that early enteral feeding is advantageous. The many nutritional problems of the short bowel syndrome have been summarised admirably elsewhere, and I propose to focus solely on the fluid and electrolyte problems of that group of patients, who not only have a short bowel, but who have also lost the reabsorptive capacity of the large bowel and terminal ileum, and whose gastrointestinal tract ends in a jejunal or mid ileal stoma. Postoperatively, parenteral nutrition is inescapable for about two months.

The following cases illustrate how the long term care of such patients at home may be assisted by the use of enteral feeding techniques.

CASE $3^{7}$

A 63 year old woman with Crohn's disease underwent several surgical procedures over five years, leaving her with an upper gastrointestinal tract and $70 \mathrm{~cm}$ of jejunum ending in a jejunostomy. There was also an isolated loop of jejuno-ileum, $150 \mathrm{~cm}$ long, opening proximally in the left abdominal wall, and ending in a stoma on the right. The surgeon wished to delay anastomosis for 12 months and sought help with nutritional support. Parenteral nutrition was started and maintained for the first four months. Subsequently, although the duodenal and jejunal remnant was sufficient for the maintenance of energy and nitrogen balance, she remained in daily negative balance of 1 litre of intestinal juice. An attempt was therefore made to restore fluid and electrolyte balance by overnight perfusion of the isolated loop of bowel with a fluid composed of 1 litre of $0.9 \%$ saline with $26 \mathrm{mmol}$ potassium chloride/l and added glucose polymer. Two physiological principles were uséd. Firstly, as shown by Sladon et al, ${ }^{8}$ neglible absorption of water or sodium takes place when the jejunum is perfused with isotonic saline at rates of $10-20 \mathrm{ml} / \mathrm{minute}$. At lower rates, however, as used in this study (less than $3 \mathrm{ml} /$ minute), absorption may take place. Secondly, as Silk has shown, ${ }^{9}$ glucose polymers can be broken down rapidly and absorbed by human jejunum; and, as in the cholera or infantile diarrhoeal mixtures, enhance the absorption of sodium. ${ }^{10}$ We therefore tested the effect of varying flow rate (Fig. 3) and the concentration of glucose polymer (Fig. 4) on the percentage absorption of the total perfusate. Ninety per cent absorption of sodium and water occurred at a perfusion rate of $150 \mathrm{ml} / \mathrm{hour}$ and with $100 \mathrm{ml}$ of polymer syrup added to each litre. At faster flow rates or with higher or lower concentrations of glucose polymer, the percentage absorption was less. The addition of magnesium hydroxide to the perfusate increased with fluid effluent. This was overcome by giving a small bolus of $10 \mathrm{mmol}$ magnesium hydroxide after the perfusion had been completed. This resulted in correction of hypomagnesaemia and maintenance of normal mag- 
Jejuno-ileal loop-flow rate $v$ output

Input: 1 litre $0.9 \%$ saline $+2 \mathrm{~g}$ potassium chloride $+100 \mathrm{ml}$ Caloreen

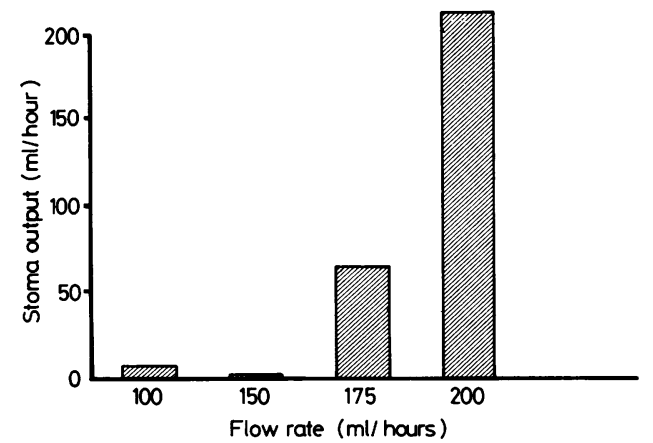

Fig. 3 Rates of stoma output per/hour during infusion of a jejuno-ileal loop with 1 litre $0.9 \%$ saline $+2 \mathrm{~g} \mathrm{kcl}+100 \mathrm{ml}$ Caloreen at rates of 100-200 ml/hour.

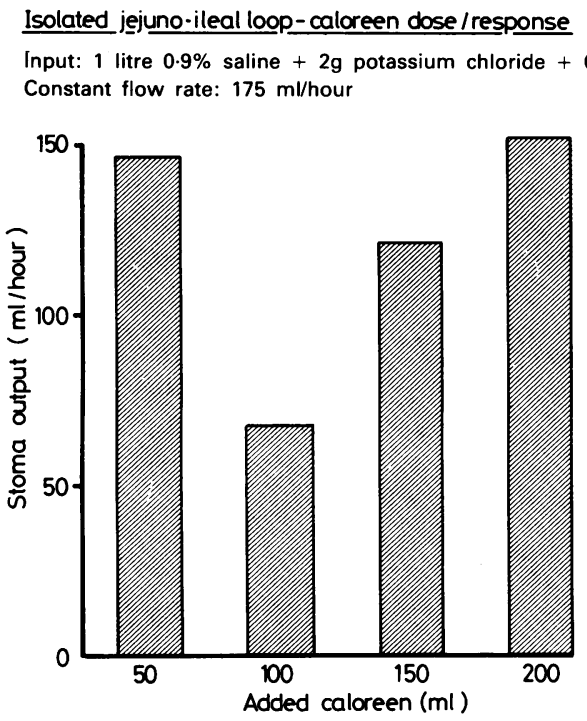

Fig. 4 Rates of stoma output per/hour during infusion of a jejuno-ileal loop at $175 \mathrm{ml} /$ hour with 1 litre $0.9 \%$ saline $+2 \mathrm{~g}$ $k c l+$ increasing volumes of Caloreen $(50-200 \mathrm{ml})$.

nesium balance. Using this technique of overnight isolated loop perfusion, the patient maintained herself in good health at home for the following 12 months. A successful reanastomosis of the bowel was then carried out.

CASE 4

In this case similar principles were used. This 40 year old man with Crohn's disease had lost all his bowel apart from $2 \mathrm{~m}$ of jejunum ending in a stoma. Various attempts had been made to sustain him by mouth, but despite these he remained $12 \mathrm{~kg}$ below his usual weight with a salt and water deficit and a jejunostomy output in excess of 3 litres/day. Parenteral nutrition was started in association with frequent small meals and an overnight nasogastric tube feed consisting of 1 litre normal saline, 1 litre of $5 \%$ dextrose, $26 \mathrm{mmol}$ of potassium chloride and $10 \mathrm{mmol}$ of magnesium hydroxide. Two cans of Nutranel containing oligosaccharide and peptides were added to enhance sodium reabsorption. Fig. 5 shows the changes in jejunostomy and urine output and the change in oral, intravenous, and overnight nasogastric intakes with time. On discharge from hospital the patient was able to sustain himself in normal calorie, nitrogen, water and electrolyte balance with small frequent meals by day and a $1500 \mathrm{ml}$ overnight nasogastric tube feed using a continuous infusion pump. He has maintained himself in this way at home for the past year and has lost no time from work. A recent viral infection resulted in a slight fluid deficit and he was readmitted for assessment. Fig. 6 shows the input and output data for sodium and water. His jejunostomy volume remained at about 2 litres/day with a constant sodium loss in the region of $170 \mathrm{mmol}$. This is amply offset by the overnight supplementation.
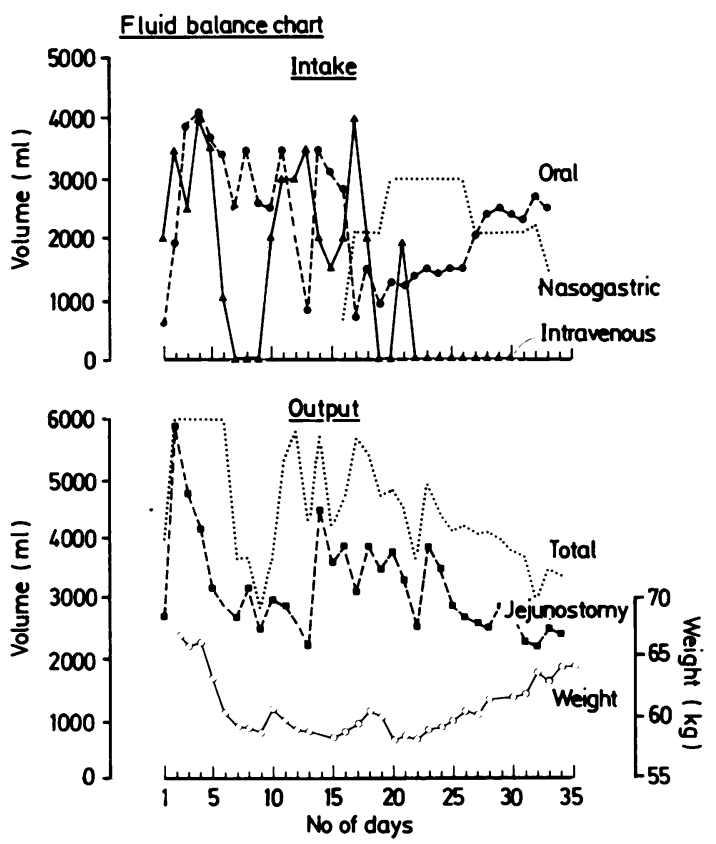

Fig. 5 Changes in fluid intake by intravenous, nasogastric, and oral routes with corresponding changes in weight, and jejunostomy and total (ileostomy + urine) output in patient with short bowel syndrome and Crohn's disease (case 4). 


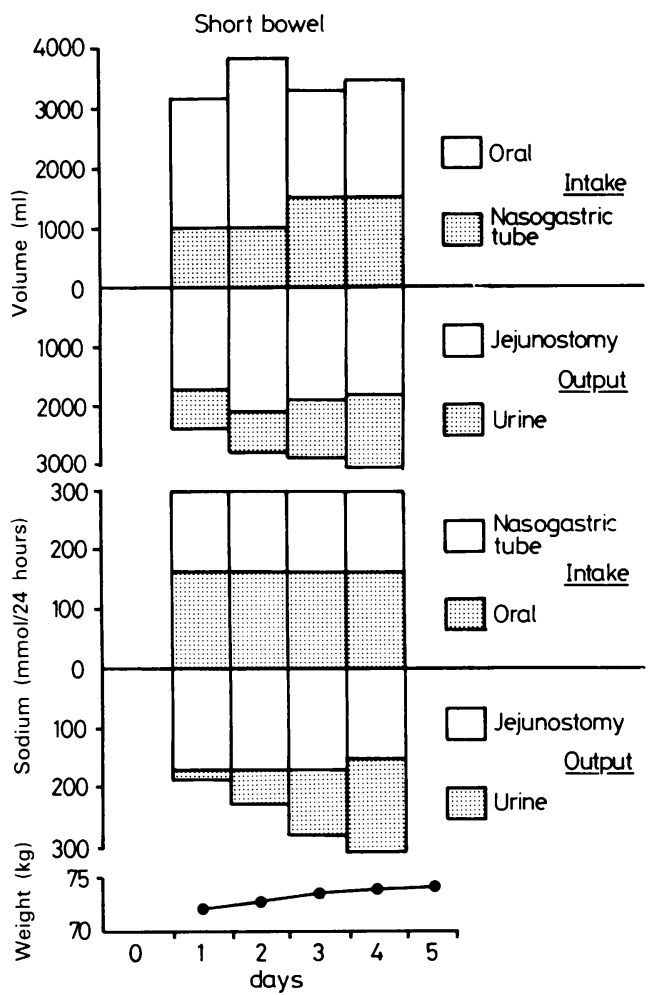

Fig. 6 Oral and nasogastric intake and jejunostomy and urine output over four days in case 4.

Although we carry out home parenteral nutrition when necessary in this department, this is financially and technically demanding, and before undertaking it we looked at the alternative of enteral supplementation. These two cases illustrate the use of physiological principles for maintaining such enteral supplementation at home. The importance of a low fat intake in this condition has been highlighted by the recent work of Andersson et al. " In a careful study of patients with short bowel they showed no advantage of peptides over whole protein in terms of nitrogen absorption or fluid losses. A considerable reduction in fluid, electrolyte, calcium and magnesium loss was achieved with a low $(4 \mathrm{~g} / \mathrm{l})$, compared with a medium $(11 \mathrm{~g} / \mathrm{l})$, or a high fat $(34 \mathrm{~g} / \mathrm{l})$ diet.

\section{Crohn's disease and bowel rest}

The beneficial effects of parenteral nutrition in Crohn's disease have been ascribed not only to the improvement in the patient's nutritional and general state, but also to resting the bowel, although there were no controlled data to distinguish the two effects. A recent paper by Lochs et al ${ }^{12}$ showed equally good clinical results whether patients were treated with parenteral nutrition alone or parenteral nutrition with free access to a low residue diet. This accords with our own clinical experience.

CASE 5

A young woman with recently diagnosed Crohn's disease suffered weight loss, seven motions a day, and right iliac fossa pain associated with terminal ileal disease. A week of hospital rest and increased steroids failed to improve her condition. Nasogastric tube feeding was attempted but produced an increase in her pain symptoms and was accordingly abandoned in favour of parenteral nutrition to supply her entire metabolic needs. She was, however, allowed to eat freely from the ward menu. Over the next three weeks her nutritional state improved with a gain in weight, and despite a reduction in steroid dose and an increase in oral intake her symptoms subsided and the number of motions per day decreased to three.

\section{Clinical benefit}

Patients who have already lost weight and whose condition precludes them eating normally for several weeks need some form of supplementary feeding, whether parenteral or enteral, as the laws
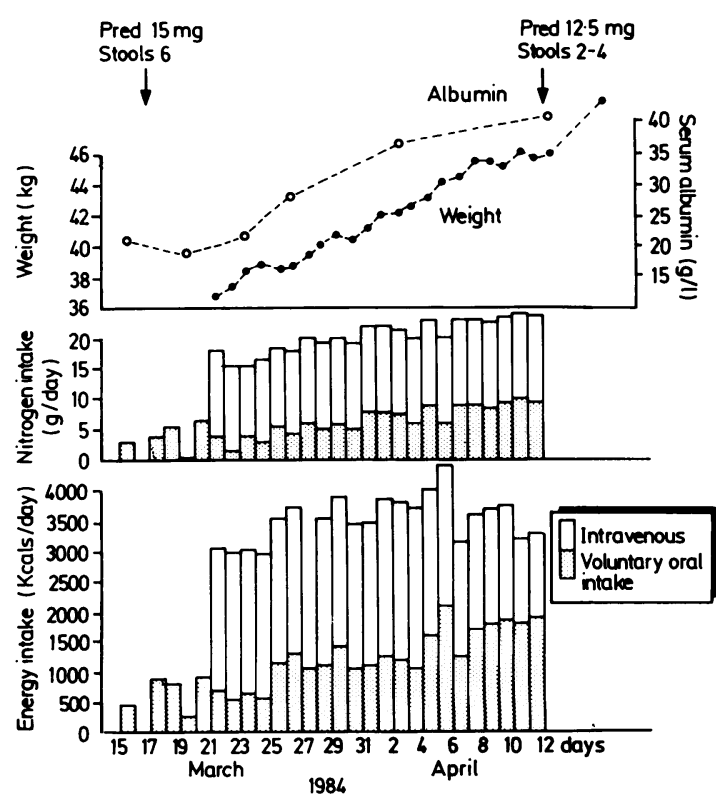

Fig. 7 Oral and intravenous intake and increases in weight and serum albumin in young woman with acute Crohn's disease. Clinical improvement occurred despite steroid reduction and absence of "bowel rest." Bowel movements reduced from six to three per day. 
Table 2 Mortality and voluntary oral intake according to nutritional state in patients with fractured femoral neck (from Bastow et al) $)^{13}$

\begin{tabular}{|c|c|c|c|c|c|}
\hline & Group & No of patients & $\begin{array}{l}\text { Age } \\
\text { (mean and range) }\end{array}$ & $\begin{array}{l}\text { Energy (kcallday) } \\
\text { intake in hospital } \\
\text { (mean and range) }\end{array}$ & Mortality $(\%)$ \\
\hline 1 & Well nourished & 351 & $79(59-93)$ & $2200(1100-3000)$ & $4 \cdot 4$ \\
\hline 2 & Thin & 255 & $83(65-102)$ & $1400(650-1800)$ & $8 \cdot 0$ \\
\hline 3 & Very thin & 138 & $81(68-96)$ & $1100(240-1400)$ & $18 \cdot 0$ \\
\hline
\end{tabular}

of thermodynamics have yet to be repealed. There are other groups, however, for whom the issue is not quite so clear cut and where prospective, randomised controlled trials are necessary to prove benefit. Unfortunately, the whole subject of clinical nutrition is bedevilled by the fact that such trials are few and far between.

The results of one such trial that we carried out illustrate one or two important points. The trial was carried out on elderly women admitted to our hospital with fractured femur. ${ }^{13}$ They were divided into three nutritional groups on the basis of weight, arm circumference, and triceps skin fold thickness. Group 1 ("well nourished") had measurements within 1 standard deviation of the mean for a comparable elderly population. Group 2 ("thin") were between 1 and 2 standard deviations below that mean, and group 3 ("very thin") were more than 2 standard deviations below the mean. The groups were of comparable age and had other comparable clinical features. Group 1 was not entered into the feeding trial as the patients were already well nourished (Table 2), and had an adequate voluntary oral intake postoperatively. One hundred and twenty five patients from groups 2 and 3 were entered into the study. Their voluntary oral intake was very much smaller than that of group 1. Tables 3 and 4 show the effect of the treatment on mortality and rehabilitation time. Rehabilitation time was assessed independently by a physiotherapist as the time between operation and independent mobility, defined as the ability to walk 6 metres

Table 3 No of patients, mean age, and mortality during hospital stay in each nutritional group

\begin{tabular}{|c|c|c|c|}
\hline Nutritional group & $\begin{array}{l}\text { No of } \\
\text { patients }\end{array}$ & $\begin{array}{l}\text { Mean age } \\
\text { in years (range) }\end{array}$ & $\begin{array}{l}\text { No }(\%) \\
\text { of deaths }\end{array}$ \\
\hline 1 & 21 & 77 (68-91) & $1(4 \cdot 8)$ \\
\hline $\int$ Control & 35 & $78(69-89)$ & $4(11 \cdot 4)$ \\
\hline $2\{$ Tube fed & 39 & $80(68-92)$ & $5(12 \cdot 8)$ \\
\hline${ }_{3}$ Control & 23 & $82(74-89)$ & $5(21.7)$ \\
\hline${ }^{3}$ Tube fed & 25 & $82(70-91)$ & $2(8-0)^{*}$ \\
\hline
\end{tabular}

Table 4 Rehabilitation time after fractured femur

\begin{tabular}{lll}
\hline $\begin{array}{l}\text { Nutritional } \\
\text { Group }\end{array}$ & $\begin{array}{l}\text { No of } \\
\text { patients }\end{array}$ & $\begin{array}{l}\text { Median } \\
\text { rehabilitation } \\
\text { time (days) }\end{array}$ \\
\hline 1 & 20 & 10 \\
$2\left\{\begin{array}{l}\text { Control } \\
\text { Tube fed }\end{array}\right.$ & 30 & 12 \\
3 & 38 & $10(\mathrm{p}=0 \cdot 04)$ \\
Control & 19 & 23 \\
Tube fed & 22 & $16(\mathrm{p}=0 \cdot 02)$ \\
\hline
\end{tabular}

${ }^{*}$ Time from operation to independent mobility $(6 \mathrm{~m})$ From Bastow et al. ${ }^{13}$

unaided. The following conclusions may be drawn from the data:

1 Voluntary oral intake was related to nutritional state on admission. The already undernourished ate very little, ensuring further deterioration in nutritional state compared with the well nourished-lack of appetite was a major problem.

2 Mortality and rehabilitation time did not rise steeply until a large degree of undernutrition (greater than 2 SD below the mean) existed. Minor degrees of undernutrition were not of great clinical importance in this type of patient.

3 A beneficial effect of supplementary nutrition on mortality and rehabilitation time was seen only in those who started with a nutritional deficit and whose oral intake was correspondingly insufficient. The shortening of rehabilitation time may be related to the improvement in the physiological function of muscle with improved nutritional state.

\section{Discussion}

Lack of appetite is a major clinical problem that can be managed successfully by enteral tube feeding, which, in contrast to parenteral nutrition, disinhibits appetite, possibly through hormonal or neural mediation. Primary anorexia is due to the disease itself; secondary anorexia results from malnutrition itself and constitutes a vicious circle of weight deficit and anorexia that can be broken by enteral feeding.

Overnight tube feeding with small volumes of 
hyperosmolar feed administered slowly by pumps is practical and free of complications in hospital and at home. Patients are thus free to exercise and eat by day.

The fluid and electrolyte deficits associated with short bowel syndrome may be successfully managed by overnight tube feeding using the physiological principles of slow flow and enhancement of sodium absorption by carbohydrates and peptides.

I suggest that bowel rest may be unimportant in the management of Crohn's disease and that treatment should be aimed at improving nutritional state by whatever route or combination of routes is available.

Finally, data from a controlled trial of overnight supplementary tube feeding in patients with fractured femur showed an appreciable shortening of rehabilitation time only in those who were very thin to start with and whose oral intake was correspondingly inadequate. Further prospective trials are needed in other types of patient to define the indications for enteral feeding.

I acknowledge the work of my colleagues Drs Tony Woolfson, Val Heatley, Simon Walford, Michael Bastow and Ian Fellows. I also pay tribute to the important contributions of Dr Hugh McMichael, ${ }^{2}$ who invented the fine bore tube and introducer wire in its present form. To him are also due some of the kinetic concepts discussed in this paper, particularly in relation to the short bowel syndrome.

\section{References}

1 Woolson AMJ, Rocketts CR, Hardy SM, Saour JM, Pollard BJ, Allison SP. Prolonged nasogastric tube feeding in critically ill and surgical patients. Postgrad Med J, 1976; 52: 687.

2 McMichael HB. Physiology of carbohydrate, electrolyte and water absorption. Research and Clinical Forums 1979; 1: 25-8.

3 Allison SP, Walford S, Todorovic V. Elliott ET. Practical aspects of nutrition support. Research and Clinical Forums 1979; 1: 49-57.

4 Bastow MD, Rawlings J, Allison SP. Overnight nasogastric tube feeding. Clin Nutr 1985; 4: 7-11.

5 Schonheyder F, Heilskov NSC, Olesen K. Isotopic studies on mechanism of negative nitrogen balance produced by immobilisation. Scand J Clin Lab Invest 1954; 6: 178-88.

6 Williamson RCN. Disuse atrophy of the intestinal tract. Clin Nutr 1984; 3: 169-70.

7 Allison SP, Williams L, Sandhar B, et al. Supplementation of nutritional, fluid and electrolyte balance by perfusion of an isolated small bowel loop in a patient with Crohn's disease. Clin Nutr 1983; 2: 107-11.

8 Sladen GE, Dawson AM. Interrelationships between the absorption of glucose, sodium and water by the normal human jejunum. Clin Sci 1969; 36: 119-32.

9 Silk DBA. Intestinal absorption of nutrients. In: Surgical nutrition, Fischer JE, ed. Boston: Little Brown \& Co, 1983: 19-64.

10 Malawer SJ, Ewton M, Fordran JS, et al. Interrelationships between jejunal absorption of sodium, glucose and water in man. J Clin Invest 1965; 44: 1972.

11 Andersson H, Bosacus I, Ellegard L, Hallgren B, Hulten L, Magnusson O. Comparison of an elemental and two polymeric diets in colectomized patients with or without intestinal resection. Clin Nutr 1984; 3: 183-9.

12 Lochs H, Meryn S, Marosi L, Ferenci P, Hortnagl H. Has total bowel rest a beneficial effect in the treatment of Crohn's disease. Clin Nutr 1983; 2: 61-4.

13 Bastow MD, Rawlings J, Allison SP. Benefits of supplementary tube feeding after fractured neck of femur: a randomised controlled trial. $\mathrm{Br}$ Med $J$ 1983; 287: 1589-92. 